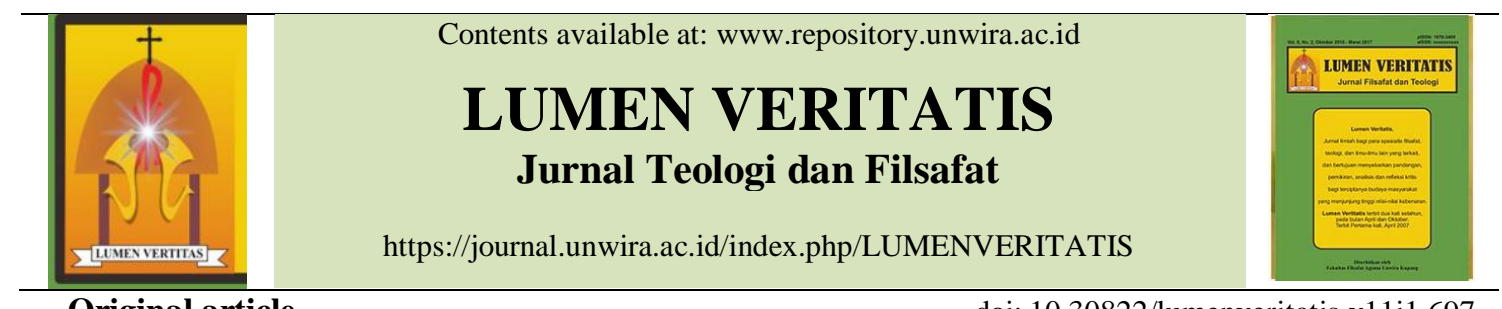

Original article

doi: 10.30822/lumenveritatis.v11i1.697

\title{
MENDALAMI GELAR-GELAR SANTA PERAWAN MARIA BUNDA ALLAH DALAM PENGAKUAN DAN AJARAN FRANSISKUS
}

\author{
Philipus Benitius Metom \\ STP Santo Petrus, Keuskupan Atambua di Kefamenanu - TTU \\ Email: lalametom@yahoo.co.id
}

\begin{abstract}
There is a line of titles of Saint Mary mentioned by Pope Francis in his published encyclicals and apostolic exortations. However, we summarize them into seven new titles, namely, Saint Mary is the daughter of Zion, mother, queen, woman, star, bride, and the spring of happiness for the little people. We consider that the number seven title has opened the minds of the faithful about the joy of believing in the Triune God who saves the world and the significant role of Saint Mary in the success of this exalted work. The recognition of the seven new titles aims to support the understanding of the faith of the Catholic faithful in the Blessed Mary as Mother of God and Virgin. Apart from that, another goal is that the quality of the Church's faith in the virginity of Saint Mary and her mother of God will be strengthened. What kind of quality do you want to affirm? What he wants to affirm is the quality of the Church's faith which is rooted in the past of the Old Testament, which is flourishing and expanding in the present, and which will bear fruit to await eternal happiness in the future (eschatological). Thus, the seven new titles of Saint Mary can reveal the faith of the Church to live at all times.
\end{abstract}

Keywords: Gelar-gelar Santa Maria, Surat Ensiklik, Eksortasi Apostolik Paus Fransiskus

\section{Pendahuluan}

Kita tahu bahwa Paus Fransiskus dalam masa pontifikatnya telah menerbitkan dan mengumumkan sejumlah ensiklik dan eksortasi apostolik, yakni Ensiklik Lumen Fidei (Terang Iman) pada tanggal 29 Juni 2013, Eksortasi Apostolik Evangelii Gaudium (Sukacita Injil) pada tanggal 24 November 2013, Ensiklik Laudato Si (Terpujilah Engkau) pada tanggal 24 Mei 2015, Eksortasi Apostolik Amoris Laetitia (Sukacita Kasih) pada tanggal 19 Maret 2016, Eksortasi Apostolik Gaudete et Exultate (Bergembiralah dan Pujilah) pada tanggal 19 Maret 2018, Eksortasi Apostolik
Christus Vivit (Kristus Hidup) pada tanggal 25 Maret 2019 dan Eksortasi Apostolik Querida Amazonia pada tanggal 2 Februari 2020. Ketujuh surat apostolik tersebut berbicara tentang tema yang berbeda-beda. Lumen Fidei membahas tentang iman Kristen yang berperan penting dalam kehidupan orang beriman di tengah pergulatan di dunia. Terang iman Kristen hendaknya dapat menerangi semua orang di dunia. Evangelii Gaudium berisi nasihat bagi kaum beriman agar melaksanakan tugas pewartaan Injil dengan sukacita. Para pewarta Injil hendaknya bersukacita dalam melaksanakan tugasnya dan tetap bergembira sekembali dari penunaian 
tugas luhur itu. Laudato Si mengarahkan perhatian orang beriman akan pentingnya mencintai alam-jagat raya dan melestarikan isinya. Sembari meneladani Santo Fransiskus Asisi, para murid Kristus dalam kehidupan dan karyanya harus selalu memperlakukan alam sebagai sahabat yang patut dihormati, dicintai dan karena itu harus dilestarikan. Amoris Laetita berisi ajaran tentang cinta kasih sejati yang harus diwujud-nyatakan dalam perkawinan suami isteri dan kehidupan keluarga. Para orang tua dan anak-anak hendaknya membina kehidupannya di atas dasar hukum cinta kasih. Gaudete et Exultate memuat penyadaran akan panggilan semua umat beriman kepada kekudusan. Setiap orang beriman dipanggil untuk mengejar dan meraih kekudusan dalam setiap profesi kerjanya dan serentak di medan laga kehidupannya. Christus Vivit menegaskan kembali pengakuan iman Kristen bahwa Yesus Kristus tetap hidup. Oleh karena itu Orang Muda Katolik hendaknya terlibat aktif dalam karya penyebarluasan Sabda Allah di berbagai sektor kehidupan manusia. Akhirnya dalam Querida Amazonia Paus Fransiskus sekali lagi mengajar secara tegas tentang pentingnya melestarikan alam-jagat raya. Baginya, alam-hutan Amazon tidak boleh dieksploitasi oleh pihak-pihak tertentu demi kepentingannya dan keuntungannya, tetapi sebaliknya harus dilestarikan dan difaedahkan demi kesejahteraan banyak orang.

Ketika membaca dan mempelajarinya, saya menemukan bahwa meskipun berbeda-beda tema, toh pada akhirnya bertemu pada uraian yang sama tentang Santa Maria. Uraian surat apostolik Lumen Fidei, Evangelii Gaudium, Laudato Si, Amoris Laetitia,
Gaudete et Exultate dan Querida Amazonia mengerucut dan memuncak pada ajakan untuk berdoa bersama Santa Maria dan meneladani keutamaankeutamaannya. Namun pada Christus Vivit, Paus Fransiskus justru menempatkan uraian tentang Maria, gadis dari Nazaret, di tengah-tengah suratnya, untuk menyusuli uraian tentang Yesus sebagai orang muda dan kemudaan Gereja. Meskipun berbeda lokasi tulisan, toh intinya yakni pengakuan iman akan Santa Maria sebagai Perawan (Virgo) dan Bunda Allah (Theotokos).

\section{Gelar-gelar Maria dalam pengakuan dan ajaran Paus Fransiskus}

Ada belasan gelar atau sebutan baru dari Santa Maria yang diakui dan diajarkan oleh Paus Fransiskus. Gelar-gelar itu berhubungan erat dengan isi atau tema dari setiap surat apostolik yang diumumkannya. Dalam ensikliknya yang pertama, Lumen Fidei, Paus Fransiskus mengakui Santa Maria sebagai Puteri Sion (LF 59), Bunda Gereja dan Bunda iman kita (LF 60). Gelar Maria sebagai Puteri Sion dihubungkan dengan kegenapan sejarah iman yang panjang dari Perjanjian Lama padamana terdapat sejumlah wanita setia yang hidup bersama dengan para bapa bangsa. Santa Maria diakui sebagai Puteri Sion yang memasrahkan dirinya pada Allah agar janji-janji Allah yang disabdakanNya di hadapan para bapa bangsa terpenuhi. Sedangkan gelar sebagai Bunda Gereja dan Bunda iman kita diakui ketika Paus mengakhiri ensiklik perdananya ini dengan doa bersama Santa Maria. Ringkasnya, Paus Fransiskus memohon bantuan pada Santa Maria untuk berdoa bagi kawanan umat gembalaan selama 
masa pontifikatnya agar mereka mendengar sabda Allah, mengenali suara panggilan Allah, dan percaya pada cinta Allah (LF 60).

Dalam surat eksortasi apostoliknya yang pertama, Evangelii Gaudium, Paus Fransiskus juga menulis sejumlah pengakuan dan ajarannya tentang gelargelar Santa Maria. Pada subbagian kedua dari Bab Kelima, Paus mengakui Santa Maria sebagai Bintang Evangelisasi baru. "Dia adalah Bunda Gereja yang mewartakan Injil, dan tanpa dia kita tak pernah dapat sungguh-sungguh memahami jiwa evangelisasi baru" (EG 284). Berkaitan dengannya, Maria diakui pula sebagai "perempuan iman, yang hidup dan berkembang dalam iman, dan peziarahan imannya yang luar biasa itu merupakan titik acuan yang terusmenerus bagi Gereja. Maria membiarkan dirinya dibimbing oleh Roh Kudus melintasi perjalanan iman menuju tujuan pelayanan dan kesuburan" (EG 287). Dialah wanita yang menyingkapkan "selubung" untuk "menghampiri Yang Tak Terlihat dan hidup secara erat dengan misteri" (EG 287). Pujaan kepada Santa Maria sebagai bintang evangelisasi baru ternyata dengan serta-merta melahirkan pula gelar-gelar lain yakni Santa Maria diakui sebagai "perempuan pendoa dan pekerja di Nazaret, Ratu yang siap dan cepat membantu, yang berangkat dari kotanya "langsung" untuk melayani sesama" (EG 288). Kebenaran atas gelar ini sekaligus melahirkan gelar-gelar lain yang disebut Paus Fransiskus dalam satu untaian doa pada akhir eksortasi apostolik ini, yakni Santa Maria diakui sebagai "Perawan yang mendengarkan dan merenungkan, Bunda cinta kasih, Mempelai perjamuan perkawinan abadi, ... Bunda Injil yang hidup, dan mata air sumber kebahagiaan bagi umat kecil Allah" (EG 288).

Dalam ensikliknya yang kedua, Laudato Si, Paus Fransiskus mengupas secara teologis-filosofis-pastoral tentang perhatian dan cinta akan lingkungan hidup. Sebagaimana sudah yang ditulis pada dua surat terdahulu, Paus tetap mengakhiri suratnya ini dengan pengakuan kepada Santa Maria sebagai Bunda yang telah merawat Yesus, dan yang sekarang merawat dunia yang terluka. Baginya, Santa Maria berdukacita atas penderitaan orang-orang miskin dan makhluk-makhluk dari dunia yang dihancurkan oleh kekuasaan manusia. Santa Maria adalah "perempuan berselubungkan matahari dengan bulan di bawah kakinya dan sebuah mahkota dari duabelas bintang di atas kepalanya" (Why 12:1). Santa Maria adalah Ibu dan Ratu seluruh ciptaan (LS 241). Santa Maria "tidak hanya menyimpan dalam hatinya seluruh kehidupan Yesus yang ia asuh dengan setia, tetapi sekarang pun ia memahami makna segala sesuatu. Oleh karena itu, kita dapat meminta Santa Maria untuk membantu kita memandang dunia ini dengan mata yang lebih bijaksana" (LS 241).

Dalam eksortasi apostolik Amoris Laetitia, Paus Fransiskus tidak menyebut gelar yang khas, tetapi menyapa Santa Maria dalam persatuan dengan Tuhan Yesus dan Santo Yusuf. "Yesus, Maria dan Yusuf, di dalam kamu kami merenungkan kemegahan cinta sejati;untuk Anda kami beralih dengan kepercayaan" (AL 325).

Dalam eksortasi apostolik Gaudete et Exultate, beliau mengakui Santa Maria sebagai "wanita yang bersukacita di hadirat Tuhan, yang menghargai segala yang ada di hatinya, dan yang membiarkan dirinya ditusuk oleh 
pedang" (GeE 176). Santa Maria adalah orang suci di antara orang-orang kudus, yang diberkati melebihi yang lainnya. Dia mengajarkan kita cara kekudusan dan dia selalu berjalan di sisi kita. Dia tidak membiarkan kita tetap jatuh dan kadangkadang dia membawa kita ke dalam pelukannya tanpa menghakimi kita (GeE 176). Paus menegaskan bahwa sebagai Bunda kita, Santa Maria tidak membutuhkan banjir kata-kata kita ketika kita mau berkomunikasi dengannya, tetapi sebaliknya hanya dengan berbisik berkali-kali dalam doa: "Salam Maria" ... (GeE 176).

Eksortasi apostolik Paus Fransiskus yang terkesan lebih pastoral ditulis dalam Christus Vivit. Di dalamnya Paus menyapa Orang Muda Katolik untuk terlibat dalam karya pewartaan Injil, sama seperti yang telah dilakukan oleh sejumlah orang muda yang dikisahkan dalam Kitab Suci, terutama Yesus Kristus. Baginya, "Yesus adalah orang muda di antara yang muda untuk menjadi teladan bagi yang muda dan menguduskan diri mereka kepada Tuhan" (CV 22). Dengan tumpuan pada Luk 3:23, Paus menegaskan bahwa Tuhan Yesus menyerahkan nyawaNya di atas salib ketika Ia baru berumur tiga puluh tahun lebih sedikit, karena itu patut untuk dipahami bahwa Yesus adalah seorang pemuda (CV 23). Penegasan di atas dengan serta-merta mengakui Santa Maria sebagai teladan unggul bagi Gereja yang muda, karena ketika ditemui malaikat Gabriel, ia masih sangat muda (CV 43) karena pada saat itu ia adalah seorang perawan dari Nazaret di Galilea, yang bertunangan dengan Yusuf dari keluarga Daud (Luk 1:26).

\footnotetext{
${ }^{1}$ Katekismus Gereja Katolik, disingkat KGK, no.
} 495.
Akhirnya dalam eksortasi apostolik Querida Amazonia Paus Fransiskus menegaskan ulang pengakuannya kepada Santa Maria sebagai "Bunda kehidupan, ratu alam ciptaan dan Bunda semua makhluk" (QA 111). Pada akhir eksortasi apostolik ini Paus Fransiskus berdoa, katanya, "Bunda kehidupan, di rahim ibumu Yesus mengambil daging, Tuhan semua yang ada. ...Tunjukkan dirimu Bunda semua makhluk, dalam keindahan bunga, sungai, sungai besar yang mengalir melaluinya dan semua kehidupan berdenyut di hutannya. ... Ibu, lihatlah kaum miskin di wilayah Amazon, karena rumah mereka dihancurkan oleh kepentingan-kepentingan tertentu" (QA 111).

\section{Suatu pendalaman}

Kami sadar bahwa pendalaman ini tidak muncul dari motivasi untuk menggeser dan itu berarti meniadakan ketegasan teologis yang sudah disinggung Paus Fransiskus dalam tujuh surat apostoliknya yang disebut di sini, tetapi sebaliknya bertujuan untuk menerjemahkan ketegasan tersebut dalam penuturan yang lebih dalam. Pendalaman ini kami buat dalam dua kategori, yakni gelar-gelar lama dan gelar-gelar baru yang diakui Gereja kepada Santa Maria.

\section{a. Gelar-gelar lama}

Paus Fransiskus tetap mengakui Santa Maria dengan gelar-gelar yang sudah lama diakui Gereja sejak abad pertama kekristenan hingga abad keempat Masehi, yakni Santa Maria sebagai Bunda Allah, Theotokos ${ }^{1}$, dan

Gelar Theotokos, Bunda yang melahirkan Yesus, Anak Allah, yang diberikan kepada Santa Maria, 
sebagai Perawan, aeipathernos ${ }^{2}$, (LF 58). Sebagai Bunda Allah, Santa Maria diakui Paus Fransiskus sebagai ikon iman yang sempurna sebagaimana yang telah lebih dahulu diakui oleh Elisabet: "Berbahagialah ia yang telah percaya" (Luk 1:45). Iman Santa Maria itu sempurna, utuh dan tak terbagi, karena ia "penuh rahmat" . Iman Santa Maria itu sempurna, utuh dan tak terbagi, karena dia tahu dan sadar akan tugas mahaberat yang harus diemban serta tidak menolak tugas tersebut ketika dijelaskan oleh malaikat Tuhan di hadapannya (Luk 1:30-37). Jadi, kesempurnaan dan keutuhan iman Santa Maria terungkap dalam ketegasannya menjawab: "Ya", "Jadilah padaku menurut perkataanmu itu" (Luk 1:38). Iman Santa Maria itu sempurna, utuh dan tak terbagi, karena dia memiliki hati yang baik bagaikan "tanah yang baik" yang menjadi tempat tumbuhnya Sabda Allah dan menghasilkan buah. Iman Santa Maria itu sempurna, utuh dan tak terbagi, karena "ia menyimpan dalam hatinya segala sesuatu yang ia dengar dan lihat sehingga sabda itu berbuah dalam hidupnya" (LF 58). Kesempurnaan dan keutuhan iman ini mengantar Gereja untuk semakin tegas-berani mengakui Santa Maria sebagai ibu yang tak bernoda, immakulata, bunda nirmala, ${ }^{5}$ kendatipun

diakui oleh Gereja dalam Konsili Konstantinopel I (381) ketika mengakui keAllahan Yesus yang sehakikat (homo-ousius) dengan Allah Bapa.

${ }^{2}$ KGK no. 499.

${ }^{3}$ KGK no. 490-493, 508.

${ }^{4}$ KGK no. 511.

${ }^{5}$ KGK no. 491.

Dalam perkembangan sejarah, Gereja menjadi sadar bahwa Maria, "dipenuhi dengan rahmat" oleh Allah (Luk 1:28), sudah ditebus sejak ia dikandung. Dan itu diakui oleh dogma "Maria Dikandung tanpa Noda Dosa", yang diumumkan diingkari oleh komunitas Kristen lain. Sebagai bukti atas militansi imannya, Paus Fransiskus tetap memperlihatkan kesetaraan atas kedua gelar tersebut, yakni selalu menyebut Santa Maria sebagai Bunda dan Perawan ${ }^{6}$ (LF 59, EG 285-288, GeE 176, QA 111).

Paus Fransiskus menggunakan term "perawan" atau "gadis" dalam dua eksortasi apostoliknya: Evangelii Gaudium dan Christus Vivit. Santa Maria dijuluki sebagai "perawan yang mendengarkan dan merenungkan" (EG 288) dan "gadis Nazaret, teladan unggul kaum muda" (CV 43). Gelar sebagai perawan yang mendengarkan dan merenungkan dapat dipetik dalam kisahkisah Yesus semenjak pemberitahuan tentang kelahiran Yesus hingga penderitaan Yesus di atas salib. Istilah yang digunakan penginjil Lukas ialah "menyimpan semua perkara itu di dalam hatinya dan merenungkannya" (Luk 2:19.51). Term "menyimpan" dan "merenungkan", menurut kami, berarti mengolah dan mengelola segala perkataan dan peristiwa yang akan terjadi pada Yesus, puteranya, terutama peristiwa naas-tragis yang menyakitkan. Oleh karena itu, Santa Maria patut diakui sebagai orang yang sungguh beriman dan kokoh dalam imannya kepada Tuhan, karena dia mampu mengolah dan

pada tahun 1854 oleh Paus Pius IX: “... bahwa perawan suci Maria sejak pertama perkandungannya oleh rahmat yang luar biasa dan oleh pilihan Allah yang mahakuasa karena pahala Yesus Kristus, Penebus umat manusia, telah dibebaskan dari segala noda dosa asal".

6 Konsili Efesus (431) menegaskan lagi keAllahan Yesus sebagaimana yang sudah diakui dalam Konsili Nicea I (325) dan Konstantinopel I (381). Penegasan ini sekaligus melahirkan pengakuan iman Gereja tentang keperawanan Maria. 
mengelola segala kesulitan hidupnya di atas landasan iman akan Tuhan. Ia adalah ibu yang meditatif dan kontemplatif, bukan karena bisa membaca dan merenungkan Sabda Allah, tetapi terutama dapat menghidupinya secara nyata (bdk. Luk 1:39-56, Kis 2:11-14). Keunggulan inilah yang patut diteladani oleh semua umat kristiani, khususnya Orang Muda Katolik.

\section{b. Gelar-gelar baru}

Kami menilai bahwa munculnya barisan gelar baru yang disinggung di atas dan juga akan disinggung di sini tidak bertujuan untuk meniadakan dua gelar besar yang sudah lama disepakati dalam syahadat iman Kristen, tetapi terutama untuk menambah kualitas pemahaman iman umat Kristen Katolik akan peranan Santa Maria dalam karya Allah menyelamatkan manusia sejak dahulu hingga sekarang, dan bahkan akan sampai pada abad-abad mendatang. Inilah uraian kritis atas tujuh gelar baru yang dikatakan Paus Fransiskus dalam tujuh surat apostoliknya.

Pertama; Maria sebagai Puteri Sion. ${ }^{7}$ Disebut di sini dua teks Perjanjian Lama yang memakai term "puteri Sion". Nabi Zefanya bernubuat katanya, "Bersoraksorailah, hai puteri Sion, bertempiksoraklah, hai Israel! Bersukacitalah dan beria-rialah dengan segenap hati, hai puteri Yerusalem!” (Zef 3:14). Hampir senada dengannya, nabi Zakharia pun

${ }^{7}$ Herbert Haag, Kamus Alkitab, Diterjemahkan dari Biblisches Worterbuch oleh Lembaga Biblika Indonesia, Ende: Nusa Indah, 2002, hlm. 415.

Kata "Sion" itu menunjuk sebuah bukti yang terletak di bagian tenggara Yerusalem. Secara etimologis, kata ini tidak terang artinya. Kata "Sion" bukan lagi sebuah nama topografis, melainkan dihubungkan dengan bukit kenizah bernubuat bahwa: "Bersorak-sorailah dengan nyaring, hai puteri Sion, bersorak-sorailah, hai puteri Yerusalem! Lihat, rajamu datang kepadamu: ia adil dan jaya. Ia lemah lembut dan mengendarai seekor keledai, seekor keledai beban yang muda" (Za 9:9). Nabi Zefania bernubuat tentang luapan kegembiraan dan sukacita warga kota Sion, kota Yerusalem, yang menantikan janji keselamatan Allah. Lebih dari itu, nabi Zakharia menjelaskan nubuatnya bahwa janji keselamatan tersebut akan menjadi genap ketika warga kota Sion, kota Yerusalem, menyambut seorang tokoh yang beridentitas sebagai seorang Raja, dan berkarakter sebagai pemimpin yang adil, jaya, lemah-lembut, karena kedatangannya menggunakan seekor keledai.

Term "puteri Sion" disebut juga di dalam Injil-Injil Perjanjian Baru. Dalam Mat 21:5 dikatakan, "Katakanlah kepada puteri Sion: Lihat, Rajamu datang kepadamu, Ia lemah lembut dan mengendarai seekor keledai, seekor keledai beban yang muda". Sedangkan bunyi petikan Yoh 12:15 yakni "Jangan takut, hai puteri Sion, lihatlah, Rajamu datang, duduk di atas seekor keledai". Jelas di sini bahwa kedua ayat Injil tersebut merupakan pemenuhan atas ramalan nabi Zefania dan nabi Zakharia. Ramalan para nabi tentang kedatangan Mesias sebagai Raja justru disaksikan langsung oleh warga kota Sion, kota Yerusalem, ketika melihat Yesus yang

dan tempat tinggal Tuhan, bahkan dihubungkan pada keseluruhan Yerusalem sebagai pusat tujuan ziarah. Para penghuni yang berdiam di dalam kota ini disebut dengan putri Sion (2Raj 19:21). Pada waktu pembuangan dan setelah pembuangan, kata Sion berarti Yerusalem sebagai kota keselamatan pada akhir zaman yang tidak dilupakan oleh Yahwe. 
memasuki kota Yerusalem dengan menunggangi seekor keledai, seekor keledai beban yang muda.

Sesungguhnya gelar "puteri Sion" pada hakekatnya disandangkan kepada warga kota Sion, kota Yerusalem, yang di dalamnya terdapat baik laki-laki maupun perempuan, baik orang tua maupun orang muda dan anak-anak. Akan tetapi Paus Fransiskus justru menggunakan term tersebut untuk menghormati Santa Maria, yang mewakili sejumlah perempuan beriman yang setia kepada Allah dan yang setia pula mendampingi suaminya yakni Abraham, Ishak dan Yakub. Ketika dijumpai malaikat Gabriel, Maria tinggal menetap di kota Nazaret yang berada di wilayah Galilea, bukan di kota Sion, kota Yerusalem, yang berada di wilayah Yudea. Namun penyandangan gelar puteri Sion pada Maria dinilai tepat, karena dalam diri Maria yang mengandung Yesus dari Roh Kudus itu memuncak sorak-sorai anak-anak Ibrani, warga kota Sion, kota Yerusalem, yang menyambut Mesias, Raja Damai.

Kedua; Maria sebagai Ibu. Sinonimnya ialah bunda. Gelar Maria sebagai ibu Yesus sudah dengan sendirinya diketahui dalam tulisan Injil tentang kisah-kisah Yesus dan tidak dipersoalkan validitasnya. Yang pernah diperdebatkan di kalangan jemaat Kristen ialah gelar Maria sebagai ibu Tuhan, Bunda Allah. Tetapi perdebatan itu berakhir dengan kesepakatan bersama bahwa Maria adalah Bunda Allah (Theotokos), dan selanjutnya membawa resiko yakni pengucilan terhadap sejumlah jemaat Kristen yang mengingkari gelar tersebut.

8 KGK no. 964; Konstitusi Dogmatis tentang Gereja Lumen Gentium, disingkat LG, artikel 59.
Kini kita mendalami gelar Maria sebagai ibu Gereja (mater ecclesia) dan Bunda iman Gereja (mater fidei ecclesia), yang dipublikasikan Paus Fransiskus dalam dua surat apostoliknya, yakni di dalam Lumen Fidei art. 60 dan Evangelii Gaudium art. 284. Gereja mengajar bahwa gelar Maria sebagai bunda Gereja didasarkan pada kisah penyaliban Yesus: "Dan akhirnya oleh Yesus Kristus itu juga, menjelang wafatNya di kayu salib, ia dikaruniakan kepada murid menjadi Bundanya dengan kata-kata ini: "Wanita, inilah anakmu" (Yoh 19:26-27). ${ }^{8}$

Kutipan di atas membenarkan bahwa Yesus memilih Maria, ibuNya, untuk menjadi ibu bagi murid yang dikasihi Yesus, termasuk juga ibu bagi semua orang yang percaya kepadaNya, ibu semua orang Kristen. Karena itu, benar diakui bahwa Maria adalah ibu Gereja (mater ecclesia), ibu bagi warga umat beriman yang percaya kepada Yesus, Putera Allah, yang dikandungnya dari Roh Kudus dan dilahirkannya. Pengakuan atas kebenaran ini dengan serta-merta menerima dan mengakui Maria sebagai ibu iman Gereja (mater fidei ecclesia), karena Gereja dibangun di atas dasar misteri salib Yesus yang adalah pusat iman Kristen. Oleh sebab ibu Maria menyaksikan penyaliban puteranya Yesus merupakan pemenuhan atas nubuat nabi Zakharia (Luk 2:34-35), maka benar bahwa iman ibu Maria adalah sumber iman Gereja (fons fidei ecclesia), dan serentak benar pula bahwa Maria adalah bunda iman Gereja (mater fidei ecclesia). Fondasi iman Gereja ini dibangun di atas dasar yang kokoh-kuat sejak awal sehingga pada saat-saat menantikan Roh Kudus, para rasul, warga 
perdana Gereja, mau "bertekun dengan sehati dalam doa bersama-sama dengan beberapa perempuan serta Maria, ibu Yesus, dan dengan saudara-saudara Yesus" (Kis 1:14). Sampai di sini Maria diakui sebagai ibu yang berdoa bersamasama dengan para pengikut Yesus, puteranya.

Santa Maria juga diakui Paus Fransiskus sebagai bunda cinta kasih (EG 288). Mengapa demikian? Jika kita mencermati kisah kelahiran Yesus dan masa kanak-kanakNya, maka dengan sendirinya kita yakini bahwa Maria, ibu Yesus, adalah ibu yang mencintai. Ia mencintai Yesus yang dilahirkannya, lalu "dibungkusnya dengan lampin dan dibaringkannya di dalam palungan, karena tidak ada tempat di rumah penginapan" (Luk 2:7). Ia penuh kasih sayang, sehingga mau membawa Yesus yang dilahirkannya itu ke Bait Yerusalem pada hari kedelapan untuk ditahirkan menurut tradisi adat agama Yahudi (Luk 2:21-40). Ia mencintai Yesus sehingga mau menyingkir ke Mesir bersama dengan Yusuf (Mat 2:13-15.19-23). Usahanya mencari Yesus yang hilang dalam perjalanan pulang dari Yerusalem ke Nazaret juga menjadi bukti penting lain bahwa Maria itu sungguh-sungguh ibu cinta kasih, ibu yang mengasihi Yesus.

Cinta kasih Santa Maria ditujukan pula kepada orang lain. Kebenaran atas pernyataan ini dapat kita cermati dalam kisah pesta perkawinan di Kana (Yoh 2:1-11). Permohonannya pada Yesus untuk menolong tuan pesta perkawinan yang kehabisan anggur (Yoh 2:1-11) adalah bukti yang membenarkan bahwa Maria adalah ibu yang penuh kasih sayang. Dia mengasihi orang yang kesulitan, yang sedang berkekurangan. Bukti-bukti di atas menegaskan kebenaran iman Paus Fransiskus bahwa Santa Maria adalah bunda Injil yang hidup (EG 288), karena dia menghidupi Injil dengan perbuatannya, dengan teladannya, yakni menyayangi Yesus dan orang-orang yang percaya pada Yesus puteranya.

Sebetulnya gelar yang diangkat oleh Paus Fransiskus menghantar kita untuk tetap mengingat di sini nasihat Santo Ambrosius: "Bunda Allah itu pola Gereja (eccelesiae typus) dalam hal iman, cinta kasih dan persatuan sempurna dengan Kristus". 9

Paus Fransiskus dalam ensiklik Laudato $\mathrm{Si}$ dengan tegas mengakui bahwa Santa Maria adalah ibu seluruh ciptaan [elevata in caelum, est Mater et Regina totius creati] (LS 241, QA 111). Bagaimana kita dapat memahami gelar ini dan kemudian mengakuinya? Benar bahwa Santa Maria adalah ibu bagi manusia yang diciptakan oleh Tuhan. Tetapi bagaimana kita dapat membuktikan bahwa Santa Maria adalah ibu bagi seluruh ciptaan, baik manusia maupun hewan, tumbuhan dan malaikat? Kami menduga bahwa gelar ini dapat dipahami dalam kerangka pemikiran tentang keAllahan Yesus dan yang kemudian merambat ke gelar Theotokos yang disandang Santa Maria. Benar diakui bahwa Yesus adalah sungguhsungguh Anak Allah dan sungguhsungguh Anak Manusia, sehingga Gereja pun percaya bahwa Santa Maria patut diakui sebagai Theotokos, ibu yang mengandung Yesus, Anak Allah. Benar bahwa Yesus, Allah Putera, menyelamatkan semua makhluk ciptaan, maka dengan sendirinya benar pula

${ }^{9}$ LG art. 63. 
bahwa Santa Maria adalah ibu bagi semua makhluk ciptaan yang diselamatkan oleh Yesus, Allah Putera, yang dikandungnya dari Roh Kudus dan dilahirkannya.

Di atas sudah disinggung bahwa Santa Maria adalah ibu Injil yang hidup. Hal ini berarti bahwa Santa Maria juga melaksanakan atau menghidupi perintah Yesus untuk mewartakan Injil: "Pergilah ke seluruh dunia, beritakanlah Injil kepada segala makhluk" (Mrk 16:15). Jika diakui bahwa Yesus memberi perintah untuk memberitakan Injil kepada segala makhluk, maka sebetulnya benar pula diakui bahwa Santa Maria, ibu Injil yang hidup, adalah ibu bagi segala makhluk (QA 111), karena itu dia adalah ibu kehidupan (QA 111) yang memberi kehidupan kepada segala makhluk.

Ketiga; Maria sebagai Ratu (LS 241, QA 111). Oleh keunggulan teladan dan imannya, Gereja terdorong untuk menyanjung Santa Maria sebagai Ratu bagi segala makhluk ciptaan. Dialah Ratu surga dan bumi, Ratu para imam, Ratu rosari, ratu para malaikat. Paus Fransiskus dalam ensiklik Laudato Si dan eksortasi apostolik Querida Amazonia menambahkan lagi satu pengakuan iman akan Santa Maria sebagai Ratu seluruh makhluk ciptaan [elevata in caelum, est Mater et Regina totius creati]. Gelar ini bertujuan untuk menegaskan keratuan Santa Maria bagi seluruh makhluk ciptaan, baik yang masih hidup dunia maupun yang sudah masuk ke dalam surga, dan dengan demikian gelar sebagai Ratu surga dan bumi tidak mungkin dan tidak dapat dipungkiri. Dengan menyematkan gelar ini, Gereja Katolik akan tetap dan selalu menjunjung tinggi Santa Maria sebagai makhluk ciptaan yang tinggi tingkatannya dan derajatnya ketimbang makhluk-makhluk ciptaan lain, karena Santa Maria adalah makhluk ciptaan yang tak berdosa (immakulata), yang tak bercela (nirmala). Gelar ini sesungguhnya patut disandang Santa Maria dan tiada hentinya disanjung padanya, karena dialah yang melahirkan Yesus Kristus yang diakui Gereja sebagai Raja Semesta Alam. Pengakuan ini sejajar dengan ajaran Gereja bahwa "Perawan tak bernoda, yang tidak pernah terkena oleh segala cemar dosa asal dan diangkat ke dalam kemuliaan di surga beserta badan dan jiwanya. Ia telah ditinggikan oleh Tuhan sebagai Ratu alam semesta, supaya secara lebih penuh menyerupai Puteranya, Tuan di atas segala tuan, yang telah mengalahkan dosa dan maut". ${ }^{10}$ Jadi, Santa Maria adalah Ratu alam semesta.

Gelar 'keratuan' dalam pandangan manusia umumnya disematkan pada tokoh masyarakat yang patut dimuliakan, tokoh yang hanya bisa memerintah apabila memerlukan sesuatu, tokoh yang harus diberi keistimewaan dalam banyak hal, termasuk tidak diperkenankan untuk terlibat dalam kerja, apalagi pekerjaan itu kasar dan kotor. Berbeda dengannya, Paus Fransiskus justru mengakui Santa Maria sebagai ratu yang siap dan cepat membantu (EG 288). Hal ini menegaskan bahwa Santa Maria itu ratu yang bisa bekerja (EG 288). Dia adalah ratu yang mau melayani, bukan dilayani. Dialah ratu yang mau menolong, berhati penyayang, mudah tergugah dan rela berkorban demi kebutuhan dan keselamatan orang lain (bdk. Yoh 2:111). Tentu saja gaya hidup seperti yang dilakukan Santa Maria sedikit sulit untuk ditiru oleh sejumlah wanita yang dijuluki

${ }^{10}$ KGK no. 966; LG 59. 
sebagai ratu. Jadi, Santa Maria adalah ratu yang menolong, karena dia bukanlah ratu yang ingat diri sendiri.

Keempat; Maria sebagai Perempuan. Santa Maria diakui sebagai perempuan atau wanita oleh Paus Fransiskus dalam surat eksortasi apostolik Evangelii Gaudium dan Gaudete et Exultate. Ditulis bahwa Santa Maria adalah perempuan iman, yang hidup dan berkembang dalam iman (EG 287); dia adalah perempuan pendoa dan pekerja (EG 288), perempuan yang bersukacita di hadirat Tuhan (GeE 176). Bagaimana kita dapat memahami gelar ini? Jawaban 'Ya' pada Allah untuk mewujudkan rencana Allah, yakni mengandung Yesus dari Roh Kudus dan melahirkanNya meskipun belum bersuami, menandakan bahwa Santa Maria adalah perempuan beriman; dialah perempuan yang hidup dan berkembang dalam iman. Bahkan semua peristiwa unik yang terjadi atas puteranya "disimpan dalam hatinya dan direnungkannya" juga dapat dipahami sebagai bukti biblis lain bahwa Santa Maria sungguh-sungguh adalah perempuan beriman; dan dia sungguhsungguh selalu beriman sehingga dapat menerima semua peristiwa yang terjadi atas puteranya.

Kita mencermati kisah pesta perkawinan di Kana: "Pada hari ketiga ada perkawinan di Kana yang di Galilea, dan ibu Yesus ada di situ; Yesus dan murid-muridNya diundang juga ke perkawinan itu. Ketika mereka kekurangan anggur, ibu Yesus berkata kepadaNya: "Mereka kehabisan anggur". Kata Yesus kepadanya, "Mau apakah engkau daripada-Ku, ibu? Saat-Ku belum tiba". Tetapi ibu Yesus berkata kepada pelayan-pelayan: "Apa yang dikatakan kepadamu, buatlah itu!" (Yoh 2:1-5). Secara literer kisah ini membenarkan bahwa Santa Maria adalah perempuan pendoa. Ia menyampaikan permohonannya kepada Allah dengan pengantaraan puteranya Yesus: "Mereka kehabisan anggur". Sesudah itu ia menyemangati para pelayan pesta untuk menanti pengabulan atas doanya: "Apa yang dikatakan kepadamu, buatlah itu". Permohonan Santa Maria adalah bukti doanya untuk membantu tuan pesta yang kehabisan persediaan anggur. Doa permohonan disampaikannya dengan penuh keyakinan, sehingga meskipun Yesus seakan-akan belum merestui: "Mau apakah engkau daripada-Ku, ibu? Saat-Ku belum tiba!", toh Santa Maria sudah memberi motivasi dan sekaligus mungkin awasan: "Apa yang dikatakan kepadamu, buatlah itu!" Kata-kata motivasinya membenarkan peranan Santa Maria sebagai seorang perempuan pendoa yang berdoa dengan penuh iman kepada Tuhan. Kata-kata awasannya menjadi pelajaran berharga bagi umat beriman bahwa Tuhan hanya bisa menolong orang-orang yang sungguhsungguh mau ditolong, karena dia membuka dirinya dan menyerahkan dirinya untuk dibantu oleh Tuhan.

Uraian tentang peranan sebagai perempuan pendoa di atas barangkali menjadi pintu masuk untuk memahami gelar Santa Maria sebagai perempuan pekerja. Pengetahuan Santa Maria tentang kehabisan anggur membuktikan bahwa dia adalah seorang pekerja, atau tepatnya sebagai seorang pelayan dalam pesta itu. Dengan menjadi pelayan atau pekerja, maka Santa Maria bisa tahu persis tentang kehabisan anggur. Jadi, dalam pesta perkawinan di Kana Santa Maria bekerja membantu tuan pesta, sehingga tahu pasti persediaan anggur. Keuletan Maria sebagai perempuan pekerja dapat ditafsir dalam 
kunjungannya ke rumah Elisabet, saudaranya. Tentu saja selama tiga bulan tinggal di rumah saudaranya itu Santa Maria turut serta membereskan pekerjaan-pekerjaan rumah tangga (Luk 1:39-56). Karena itu, tidak dapat disangkal bahwa Santa Maria adalah perempuan pekerja, yang bekerja untuk menyelamatkan jiwa-jiwa. Bantuannya bagi tuan pesta yang berkekurangan anggur menegaskan pula predikat Santa Maria sebagai mata air sumber kebahagiaan bagi umat kecil Allah (EG 288).

Kelima; Maria sebagai Mempelai. Term "mempelai" berkaitan sangat erat dengan adanya peristiwa perkawinan. Jika Santa Maria diberi gelar sebagai mempelai, maka benar bahwa dia adalah mempelai wanita dari seorang mempelai pria. Paus Fransiskus mengakui bahwa Santa Maria adalah mempelai perjamuan perkawinan yang abadi (EG 288). Dalam suatu penglihatan Yohanes melihat bahwa akan terselenggara suatu perjamuan perkawinan abadi padamana Tuhan Yesus tampil sebagai Mempelai Pria (Why 19:6-9), tetapi tidak jelas siapakah yang akan menjadi mempelai wanitanya. Hal tentang rencana adanya langit baru dan bumi yang baru dikatakan dalam penglihatan Yohanes bahwa "Yerusalem yang baru, yang turun dari sorga, dari Allah, yang berhias bagaikan pengantin perempuan yang berdandan untuk suaminya" (Why 21:2). Juga seorang malaikat berkata kepada Yohanes, "Marilah ke sini, aku akan menunjuk kepadamu pengantin perempuan, mempelai Anak Domba" (Why 21:9). Siapakah mempelai wanita yang akan ditunjuk untuk bersanding dengan Yesus, Mempelai Pria, pada hari perkawinan Anak Domba? Kedua kutipan di atas memastikan jawaban bahwa mempelai wanita yang pas untuk bersanding dengan Yesus pada perkawinan abadi Anak Domba adalah Yerusalem yang baru. Gereja setuju bahwa dirinya sendiri adalah Yerusalem baru. Karena itu, ditetapkan bahwa Gereja adalah mempelai Kristus. Ia adalah pengantin wanita tanpa cacat dari Anak Domba tanpa cacat. ${ }^{11}$ Jadi, mempelai wanita bagi Kristus, mempelai pria, adalah Gereja. Lalu, mengapa Paus Fransiskus mengakui Santa Maria sebagai mempelai perjamuan perkawinan yang abadi (EG 288)? Kami menduga bahwa pengenaan gelar "mempelai perjamuan perkawinan abadi" yang ditegaskan Paus Fransiskus bagi Santa Maria dimaksudkan untuk memperlihatkan keterkaitannya yang erat dengan kebenaran ajaran Gereja Katolik bahwa Santa Maria adalah mempelai wanita yang menerima semua umat beriman untuk masuk ke dalam pesta perjamuan abadi di surga. Gelar ini cocok untuk Santa Maria karena dia adalah "orang suci di antara orang-orang kudus" (GeE 176).

Keenam; Maria sebagai Bintang. Gelar 'bintang' bagi Santa Maria sudah diakui Gereja, sehingga acapkali terucap sebutan, yakni Maria bintang laut (stella maris), Maria bintang rahmat (stella gratia), Maria bintang yang bercahaya (stella duce) dan Maria bintang timur (stella oriens). Pada akhir seruan apostolik Evangelii Gaudium, Paus Fransiskus menambahkan gelar bagi Santa Maria sebagai bintang evangelisasi baru (EG 288). "Dia adalah Bunda Gereja yang mewartakan Injil, dan tanpa dia kita tak pernah dapat sungguh-sungguh

${ }^{11}$ KGK no. $796,808$. 
memahami jiwa evangelisasi baru" (EG 284).

Apa yang kita perlu pahami tentang gelar "bintang evangelisasi baru" bagi Santa Maria? Setelah dijumpai malaikat Gabriel, Santa Maria dengan sangat yakin menyatakan kebesaran karya Tuhan bagi dunia. Di hadapan Elisabet yang mengakuinya sebagai "Bunda Allah" (Luk 1:43), Santa Maria memproklamasikan tiga revolusi penting, yang menciptakan perubahan sangat besar dalam kehidupan manusia di dunia. Pertama; revolusi moral: "Ia telah memperhatikan kerendahan hambaNya, ... Ia memperlihatkan kuasaNya dengan perbuatan tanganNya dan menceraiberaikan orang yang congkak hatinya" (Luk 1:48.51). Kedua; revolusi sosial: "Ia menurunkan orang-orang yang berkuasa dari takhtanya dan meninggikan orangorang yang rendah" (Luk 1:52). Ketiga; revolusi ekonomi: "Ia melimpahkan segala yang baik kepada orang yang lapar; dan menyuruh orang yang kaya pergi dengan tangan hampa" (Luk 1:53). ${ }^{12}$ Ketiga revolusi tersebut merupakan intisari evangelisasi, yakni pewartaan khabar baik dari Allah untuk menyelamatkan manusia, dan Santa Maria justru membenarkan bahwa Allah berpihak membela orang-orang yang kecil-rendah, lemah, lapar, karena mereka berkekurangan dalam banyak hal sebagai akibat dari praktek penindasan dan ketidakadilan, sebaliknya Allah sendirilah yang akan mengalahkan orangorang yang berkuasa, yang congkak hatinya dan yang kaya-raya.

Mengapa Santa Maria diakui sebagai bintang evangelisasi? Paus Fransiskus

\footnotetext{
12 William, Barclay, The Daily Bible Study: The Gospel of Luke, Edinburgh, The Saint Andrew Press, 1975, pp. 15-16.
}

menyebut empat sifat baik yang dimiliki oleh Santa Maria, yakni rendah hati, lemah-lembut, kontemplatif karena menyimpan semua perkara di dalam hati dan merenungkannya, serta mengadakan perjalanan untuk membantu orang lain. "Di dalam diri Maria kita melihat bahwa kerendahan hati dan kelembutan bukanlah keutamaan-keutamaan dari orang yang lemah, tetapi dari orang yang kuat yang tidak perlu memperlakukan orang sebagai secara buruk agar merasa dirinya penting" (EG 288). Santa Maria menginjili dunia dengan kerendahan hati dan kelembutannya. Sikap ini tidak dimiliki oleh para pembesar dan tokohtokoh populer lain. "Dinamika keadilan dan kelembutan ini, kontemplasi dan perjalanan menuju orang-orang lain adalah apa yang membuat Maria menjadi teladan Gereja untuk evangelisasi" (EG 288). Selain kerendahan dan kelembutannya, keunggulan sifat Santa Maria yang menjadi berita gembira ialah kebiasaannya berkontemplasi dan perjalanannya untuk pergi membantu orang lain. Di sini terlihat jelas keseimbangan gaya hidup dari orangorang yang terlibat dalam karya pewartaan Injil. Aksi untuk berjalan mencari orang-orang miskin dan berkekurangan untuk dibantu harus didasarkan pada kontemplasi. Oleh karena Santa Maria menjalankan secara seimbang aksi (laborare) dan kontemplasi (orare), maka dia patut dijuluki sebagai bintang evangelisasi. Para pewarta Injil tidak boleh hanya mengutamakan aksi, lalu mengabaikan kontemplasi, karena jika demikian, maka karya itu akan memberi kesan sekedar 
sebagai karya sosial-profan sebagaimana yang juga dilakukan oleh lembagalembaga sosial kemasyarakatan. Namun jika para pewarta Injil hanya mengutamakan kontemplasi, maka keselamatan akan dikungkung demi kesucian diri sendiri dan akibat negatif lain ialah perhatian dan karya untuk menyelamatkan orang lain dinomorduakan. Santa Maria patut diteladani oleh anggota-anggota Gereja, terutama para pewarta Injil, sebagai bintang evangelisasi, agar aksi dan kontemplasi dijalankan selarasseimbang. Jadi, kebaruan yang patut dicontohi dari Santa Maria adalah kerendahan hati, kelembutan, keselarasan aksi dan kontemplasi.

Ketujuh; Maria sebagai mata air sumber kebahagiaan bagi umat kecil (EG 288). Gelar "mata air" (fons) membawa kita untuk terlebih dahulu mengingat dan mendalami kisah perjumpaan Yesus dengan wanita Samaria di sumur Yakub (Yoh 4:1-42). Dalam percakapan mereka, Yesus berkata kepada wanita Samaria, "Barangsiapa minum air ini, ia akan haus lagi, tetapi barangsiapa minum air yang akan Kuberikan kepadanya, ia tidak akan haus untuk selama-lamanya. Sebaliknya air yang akan Kuberikan kepadanya akan menjadi mata air di dalam dirinya, yang terus menerus memancar sampai kepada hidup yang kekal" (ay 13-14). Ketika mendengar satu pesan baru dan aneh tetapi menggembirakan, karena Yesus menawarkan satu jenis air yang sekali diminum orang, tidak dahaga lagi selama-lamanya, wanita itu menjawab katanya, "Tuhan, berikanlah aku air itu, supaya aku tidak haus dan tidak usah datang lagi ke sini untuk menimba air" (ay. 15). Semua orang Kristen tentu sependapat bahwa percakapan tadi menjelaskan kebenaran bahwa Yesus adalah mata air hidup, dan terutama Yesus adalah air hidup. Kata-kataNya membawa kesegaran bagi wanita Samaria melebihi air yang dia timba dari dalam sumur Yakub. Kata-kata segar tersebut menimbulkan kebahagiaan baginya, sampai dia percaya bahwa Yesus yang bercakap-cakap dengannya adalah Kristus. Selanjutnya kata-kata segar itu menjadi daya dorong yang kuat, sehingga dia bersemangat untuk memanggil banyak orang dari dalam kota Sikhar untuk melihat dan mendengar Yesus. Yang paling penting dari semuanya ialah kata-kata segar Yesus menumbuhkan iman bagi orang-orang Samaria, "Kami percaya, tetapi bukan lagi karena apa yang kaukatakan, sebab kami sendiri telah mendengar Dia dan kami tahu, bahwa Dialah benar-benar Juruselamat dunia" (ay. 42). Inilah puncak tertinggi dari perjumpaan Yesus dengan orang-orang Samaria. Kendatipun dijauhi orang-orang Yahudi, toh mereka dijumpai oleh Yesus dan karena itu percaya padaNya sebagai Mesias. Jadi, gelar Yesus sebagai air hidup yang diketahui oleh seorang wanita Samaria membawa hasil berlipat-lipat yakni orang-orang Samaria percaya bahwa Yesus adalah Juruselamat dunia. Sampai di sini terlihat jelas hubungan yang erat antara pengetahuan indrawi, pengetahuan rasional dan iman.

Menarik bahwa Paus Fransiskus menjuluki dan mengakui Santa Maria sebagai "mata air sumber kebahagiaan bagi umat kecil" (EG 288). Bila kita mencermati kisah-kisah alkitabiah, barangkali julukan dan pengakuan ini memperoleh landasan pada empat perikop yang disebut di sini, yakni kisah tentang gembala-gembala di padang Bethlehem (Luk 2:8-20), perkawinan di Kana (Yoh 2:1-11), penyaliban Yesus 
(Yoh 19:25-27) dan penantian rasul-rasul (Kis 1:12-14). Setelah melahirkan Yesus, Santa Maria menjadi sumber kegembiraan dan kebahagiaan bagi para gembala yang datang menemui mereka, karena mereka kembali sambil memuji dan memuliakan Allah, karena segala sesuatu yang didengar dan dilihat sesuai dengan kata-kata malaikat Tuhan. Ketika berkelimpahan anggur buatan Yesus berkat bantuan Santa Maria, tuan pesta Kana niscaya bergembira karena kesulitannya mendapat jalan keluar. Pada saat-saat terakhir kehilangan Yesus yang disalibkan, murid yang Dia kasihi itu sedikit bergembira karena dia harus menjadikan Santa Maria sebagai ibunya. Akhirnya ketika sedang ketakutan pasca kebangkitan Yesus sembari menantimenanti datangnya Roh Kudus, para murid Yesus bersandar pada Santa Maria yang tetap tegar dan teguh beriman untuk bersama-sama memanjatkan doa kepada Tuhan. Keempat kisah ini dapat membenarkan bahwa Santa Maria adalah mata air yang menyegarkan, sumber air yang membahagiakan orang-orang kecil yang bersandar pada Tuhan. Dialah ibu mesianik karena menghantar orang-orang kecil untuk percaya pada Yesus, Mesias.

Di samping keempat kisah biblis yang telah disebutkan di atas, ada juga sejumlah besar fakta tentang pengalaman orang-orang beriman pada Santa Maria sebagai mata air sumber kebahagiaan bagi orang-orang kecil. Pengabulan atas sejumlah doa permohonan orang-orang kecil yang disampaikan kepada Tuhan dalam doa bersama Santa Maria merupakan bukti-bukti yang telah mendukung kebenaran iman umat Kristen Katolik bahwa Santa Maria adalah mata air sumber kebahagiaan. Jadi, pertolongan Santa Maria sungguhsungguh merupakan mata air hidup yang menyegarkan orang-orang yang haus, menyirami semangat hidup orang-orang yang tampak layu dan loyo, membawa kesuburan bagi orang-orang kecil yang hampir mati imannya dan mengobarkan semangat misioner bagi mereka untuk menghasilkan buah-buah kebaikan yang berguna bagi keselamatan diri sendiri dan orang lain.

\section{Kesimpulan}

Secara literer, ada delapanbelas gelar Santa Maria yang disebut oleh Paus Fransiskus dalam surat ensiklik dan eksortasi apostoliknya. Akan tetapi kami merangkumnya menjadi tujuh gelar baru, yakni Santa Maria adalah puteri Sion, ibu, ratu, perempuan, bintang, mempelai, dan mata air sumber kebahagiaan orangorang kecil. Kami menilai bahwa angka tujuh gelar tersebut telah membuka wawasan berpikir umat beriman tentang sukacitanya karena percaya kepada Allah Tritunggal yang menyelamatkan dunia dan akan peranan Santa Perawan Maria, Bunda Allah, yang sungguh berarti dalam menyukseskan karya mahaluhur tersebut. Angka tujuh gelar tidak dimaksudkan untuk menentang angka tujuh dukacita Maria, dan bahkan mengingkarinya, tetapi sebaliknya untuk melengkapi kepenuhan iman Gereja akan Santa Maria, Perawan dan Bunda Allah. Tujuh dukacita Maria selalu dikaitkan dengan tujuh kisah Yesus, puteranya, yang diakui sebagai Tuhan dan Juruselamat. Sebaliknya mudah-mudahan tujuh gelar baru yang disematkan pada Santa Maria ini bisa dinamai sebagai tujuh sukacita Maria.

Pengakuan Paus Fransiskus tentang tujuh gelar baru bagi Santa Maria tidak dapat menggantikan dua gelar terdahulu 
yakni sebagai Bunda Allah dan sebagai Perawan. Sebaliknya pengakuan tersebut bertujuan untuk menambah kualitas iman orang Kristen Katolik akan Santa Maria dan peranannya yang sungguh berarti dalam kehidupan Gereja pada masa sekarang hingga akhir zaman.

Tujuh gelar yang diakui Paus Fransiskus dapat meneguhkan kualitas iman Gereja akan keperawanan Santa Maria dan kebundaAllahannya. Kualitas apa yang ingin diteguhkan? Yang ingin diteguhkan ialah kualitas iman Gereja yang berakar pada masa lampau Perjanjian Lama, Gereja yang bertumbuh subur dan berkembang luas pada masa sekarang, serta Gereja yang berbuah untuk menanti kebahagiaan kekal pada masa yang akan datang (eskatologis). Gelar Santa Maria sebagai "puteri Sion" berkaitan erat dengan masa Perjanjian Lama, padamana kota Sion, Yerusalem, bersukacita karena mengharapkan kehadiran Tuhan, Sang Mesias, untuk membebaskan bangsa Israel. Gelar Santa Maria sebagai bunda kita, bunda iman, bunda cinta kasih, bunda kehidupan, bunda semua makhluk, ratu seluruh makhluk ciptaan, perempuan beriman, perempuan pendoa dan pekerja, wanita yang bersukacita di hadirat Tuhan, bintang evangelisasi baru, mata air sumber kebahagiaan orang-orang kecil, berkaitan erat dengan kehidupan gereja yang sedang hidup pada masa sekarang, bertumbuh subur di ladang anggur Tuhan dan berkembang luas di seluruh dunia. Akhirnya gelar Santa Maria sebagai "Mempelai" dalam perjamuan nikah abadi Anak Domba, dan sebagai orang suci di antara para orang kudus, berkaitan erat dengan kegembiraan umat beriman yang selalu merindukan keselamatan yang akan dialaminya pada akhir zaman. Jadi, ketujuh gelar baru Santa Maria dapat menyingkap iman Gereja untuk hidup pada segala waktu, yakni waktu lampau, waktu sekarang dan waktu akan datang.

\section{Saran}

Kami berharap agar gelar-gelar Santa Maria yang telah diuraikan secara mendalam pada tulisan ini dapat diterima ke dalam satu daftar baru tentang Doa Litani Santa Maria, karena gelar-gelar baru yang diakui Paus Fransiskus dan diajarkannya ternyata sangat menyokong gelar keperawanan dan kebundaAllahan Santa Maria. Akhirnya tulisan ini kami tutup dengan menawarkan satu rumusan doa litani di bawah ini:

\section{Doa Litani Santa Maria}

Santa Maria, Bunda Allah, doakanlah kami.

Dikau yang tetap perawan, doakanlah kami.

Dikau yang disapa sebagai puteri Sion, doakanlah kami.

Dikaulah Bunda kami,

Dikaulah Bunda iman Gereja,

Dikaulah Bunda iman kami, doakanlah kami. doakanlahkami. doakanlah kami.

Dikaulah Bunda segala makhluk, doakanlah kami.

Dikaulah Ratu alam semesta doakanlah kami. doakanlah kami.

Dikaulah Ratu seluruh makhluk ciptaan, doakanlah kami.

Dikaulah Perempuan beriman, doakanlah kami.

Dikaulah Perempuan yang hidup dan berkembang dalam iman,

doakanlah kami. 
Dikaulah Perempuan pendoa,

Dikaulah Perempuan pekerja,

doakanlah kami.

doakanlah kami.

Dikaulah Perempuan yang bersukacita di hadirat

Tuhan,

doakanlah kami.

Dikaulah Mempelai nirmala Anak Domba,

doakanlah kami

Dikaulah yang tersuci di antara para orang kudus,

doakanlah kami.

Dikaulah Bintang evangelisasi baru,

doakanlah kami.

Dikaulah mata air sumber kebahagiaan bagi orang-orang kecil,

doakanlah kami.

\section{Daftar Pustaka}

Alkitab Deuterokanonika, Terjemahan Kerjasama Lembaga Biblika Indonesia dan Lembaga Alkitab Indonesia, Jakarta: Lembaga Biblika Indonesia, 2000.

Barclay, William, The Daily Bible Study: The Gospel of Luke, Edinburgh, The Saint Andrew Press, 1975.

Browning, W.R.F., Kamus Alkitab, Diterjemahkan dari A Dictionary of the Bible oleh Liem Khiem Yang et Bambang Subandrijo, Jakarta: BPK Gunung Mulia, 2007.

Dokumen Konsili Vatikan II, Diterjemahkan dari naskah resmi bahasa Latin oleh R. Hardawiryana, Jakarta: Obor \& Departemen Dokumentasi dan Penerangan Konferensi Waligereja Indonesia, 1993.

Fransiskus, Paus, Ensiklik Lumen Fidei, Diterjemahkan dari Encyclical Letter Lumen Fidei of the Supreme Pontiff Francis to the Bishops, Priests and Deacons Consecrated Persons and the Lay Faithfull on Faitholeh Alb. Deby Setiyanto, Yogyakarta: Kanisius, 2014.

Seruan Apostolik

Evangelii Gaudium, Diterjemahkan dari vatican.va edisi bahasa Inggris dan Italia (dengan perbandingan bahasa Perancis dan Jerman) oleh F.X. Adisusanto et Bernadeta Harini Tri Prasasti, Jakarta: Departemen Dokumentasi dan Penerangan Konferensi Waligereja Indonesia, Juli 2014.

, Ensiklik Laudato Si,

Diterjemahkan dari vatican.va edisi bahasa Perancis dan Italia (dengan perbandingan bahasa Inggris) oleh Martin Harun, Jakarta: Departemen Dokumentasi dan Penerangan Konferensi Waligereja Indonesia, Januari 2016.

, Seruan Apostolik

Amoris Laetitia, Diterjemahkan dari vatican.va edisi bahasa Inggris (dengan perbandingan bahasa Italia dan Perancis oleh Komisi Keluarga dan Couples for Christ Indonesia, Diedit oleh F.X. Adisusanto \& Bernadeta Harini Tri Prasasti, Jakarta: Departemen Dokumentasi dan Penerangan Konferensi Waligereja Indonesia, Februari 2018. ertationGaudete et Exultate, dari vatican.va edisi bahasa Inggris, Roma: Vatican Press, Maret 2018.

ApostolikChristus

Seruan

Diterjemahkan dari vatican.va edisi bahasa Italia (dengan perbandingan bahasa Inggris) oleh Agatha Lydia Natania, Jakarta: Departemen Dokumentasi dan Penerangan 
Konferensi Waligereja Indonesia, Haag, Herbert, Kamus Alkitab, Juli 2019. Diterjemahkan dari Biblisches Post Synodal Apostolic ExhortationQuerida Amazonia, dari vatican.va edisi bahasa Inggris, Roma: Vatican Press, Februari 2020. Worterbuch oleh Lembaga Biblika Indonesia, Ende: Nusa Indah, 2002. Katekismus Gereja Katolik, Diterjemahkan berdasarkan edisi Jerman oleh Herman Embuiru, Ende: Provinsi Gerejani Ende, 1993. 
LUMEN VERITATIS: Jurnal Filsafat dan Teologi, Volume. 11 Nomor 1 Oktober 2020

pSSN 1978-3469; eISSN 2657-1927 